\title{
EMERGING TECHNOLOGIES
}

\section{Implantable Devices in the Coronary Artery From Metal to Genes}

\author{
David W.M. Muller and Eric J. Topol
}

Preliminary data from nonrandomized clinical trials suggest that, in selected subgroups of patients, the implantation of endovascular stents may improve the initial results of coronary dilatation, may successfully treat arterial dissection and abrupt closure, and may reduce the incidence of recurrent stenosis. The widespread use of stents remains limited, however, by the need for intensive anticoagulation to prevent arterial thrombosis. The development of sustained-release drug delivery systems and gene-transfer technology may enable local delivery of antithrombotic and antiproliferative therapies that would greatly increase the safety and applicability of these devices. (Trends Cardiovasc Med 1991; 1:225-232)

Over the past decade, the options available for the management of symptomatic coronary artery disease have increased considerably. In addition to surgical revascularization, several percutaneous procedures, including balloon angioplasty, laser ablation, atherectomy, and endovascular stenting, have been evaluated clinically and have proved to be effective in relieving obstructive coronary stenoses (Karsch et al. 1990; Safian et al. 1990; Schatz et al. 1991). The long-term efficacy of each of these procedures remains limited, however, by recurrent stenosis due to neointimal thickening, a process that appears to be resistant to a variety of systemic pharmacologic therapies (Liu et al. 1989; Califf et al. 1990). As more detailed information has become available about the histopathology of restenosis following these interventions, and the cellular

David W.M. Muller is at the Division of Cardiology, Department of Internal Medicine, University of Michigan Medical Center, Ann Arbor, MI 48109, USA. Eric J. Tupol is at the Department of Cardiology, Cleveland Clinic Foundation, Cleveland, OH 44195, USA. and molecular mechanisms that contribute to its development, the attention of many investigators has turned to the possibility of combining mechanical interventions, such as endovascular stenting, with local pharmacologic therapy to control the events that follow arterial injury. This review summarizes the prospects for the therapeutic control of coronary arterial disease with implantable intravascular devices and with procedures that provide chronic, sustained release of local drug therapies.

\section{- Rationale for Endovascular Therapy}

Percutaneous coronary balloon angioplasty, the most frequently performed coronary interventional procedure, can be accomplished with a high acute success rate (Detre et al. 1989). The procedure remains limited, however, by the risk of medial dissection and abrupt coronary occlusion, and by recurrent stenosis at the site of balloon dilatation. The incidence of abrupt closure following balloon angioplasty is $-6 \%-7 \%$ (Detre et al. 1989) and restenosis occurs within
6 months of angioplasty in $35 \%-45 \%$ of patients treated (Califf et al. 1990). Postmortem histologic studies of patients dying several months after balloon angioplasty have shown that the predominant cause of restenosis is extensive neointimal thickening due to smooth muscle cell proliferation at sites of disruption of atheromatous plaque and the underlying media (Austin et al. 1985; Essed et al. 1983). The factors that influence this proliferative response remain poorly understood. It is likely that any injury that exposes subintimal components of the vessel wall will stimulate the adhesion and activation of platelets, local thrombus formation, and the release of growth factors. Mitogenic factors, derived from platelets, macrophages, and the endothelium, promote medial smooth muscle cell proliferation and migration, and the synthesis and secretion of connective tissue matrix (Liu 1989). Preliminary data suggest that this process occurs to a similar degree and with a similar time course following balloon angioplasty, coronary atherectomy, laser ablation, and endovascular stenting (Waller et al. 1990).

These observations suggest that no mechanical device will eliminate the proliferative response to injury. In theory, however, endovascular stenting offers several advantages over other methods of percutaneous revascularization. First, the stents provide an intravascular scaffold to oppose the vasoconstriction and recoil that commonly follow halloon angioplasty (Fischell et al. 1988) and that may be responsible for the recurrence of some stenoses (Waller 1985). Second, intravascular stents may minimize the extent to which subintimal tissues are exposed to the circulation by compressing dissected layers of the arterial wall, thereby reducing the stimulus to intimal proliferation. Third, by optimizing the caliber of the diseased arterial segment after dilatation, stenting may minimize the physiologic significance of any intimal thickening that does subsequently occur (Ellis et al. 1990a). Finally, although not yet reported in in vivo models, the implantation of polymeric stents or polymer- 


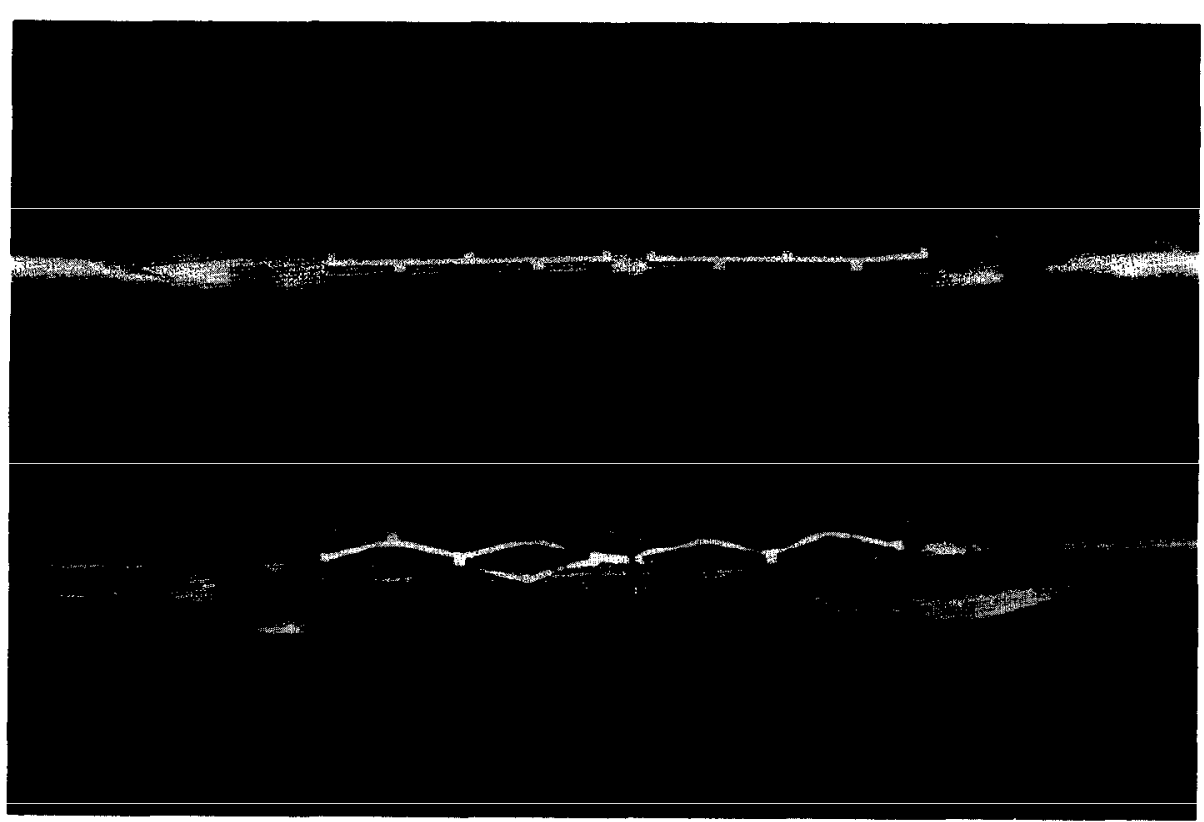

Figure 1. The articulated Palmaz-Schatz coronary stent before and after balloon inflation. From Muller et al. (1990a).

coated metallic stents may enable the delivery of high-concentration, local pharmacologic agents at the site of vascular injury. To date, the potential of this combined mechanical and pharmacologic approach to optimize both the short- and long-term efficacy of percutaneous coronary revascularization remains speculative, as several technical considerations, outlined below, have slowed the development of such devices. On the other hand, considerable clinical and experimental experience has been accumulated with the implantation of uncoated metallic stents; considerably less experience has been accumulated with stents made from synthetic polymers.

\section{- Metallic Stents}

The implantation of metallic stents was originally conceived as a means of maintaining arterial patency following dilatation of obstructive stenoses more than 20 years ago (Dotter 1969). The major advantage of metal over other materials is its high long-term structural integrity combined with a relatively low profile and small surface area. The principal disadvantages of these materials, on the other hand, include their relative inflexibility, their propensity for thrombosis, and the susceptibility of some metals to corrosion. Other considerations in the selection of the stent material include its Muller and Ellis (1990b). radiopaque than stainless steel, also has elastic properties that make it suitable for balloon delivery, hut, like stainless steel, tantalum is also thrombogenic (Bertrand et al. 1990). The metallic stents vary not only in the materials employed, but also in the mechanism of deployment. These mechanisms include balloon expansion, self-expansion, and activation by temperature-dependent changes in metal configuration (thermal memory stents).

\section{Balloon-Expandable Stents}

At least six balloon-expandable stents are currently under clinical or preclinical evaluation for implantation in coronary arteries. The Palmaz-Schatz stainlesssteel stent (Johnson and Johnson Interventional Systems, Warren, NJ, USA) has a slotted, tubular configuration prior to deployment. During balloon expansion, it takes on a rigid, diamond-mesh appearance (Figure 1). The stent is 15 $\mathrm{mm}$ long and has a $1-\mathrm{mm}$ articulation at its center to enable greater flexibility during positioning and deployment. A 5 French outer sheath is used to protect the stent and to prevent its dislodgment from the balloon catheter during implantation. Prior to balloon inflation, the sheath is withdrawn to enable unrestricted balloon and stent expansion at

Figure 2. The Gianturco-Roubin coronary stent before and after balloon inflation. From

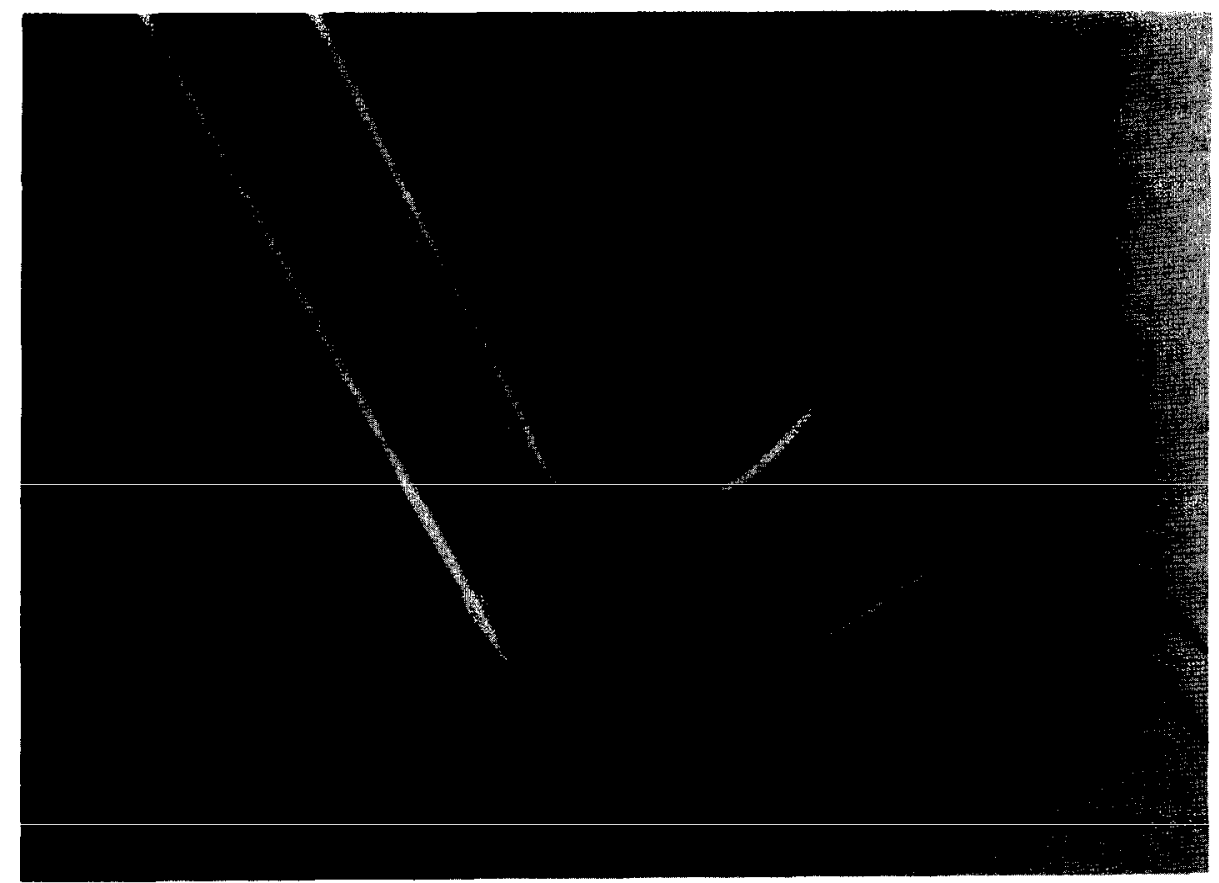


the site of the coronary stenosis. The Gianturco-Roubin stent (Cook Inc., Bloomington, IN, USA) is $20 \mathrm{~mm}$ long and has an interdigitating coil configuration (Figure 2). Two versions of the stent, one stainless steel and one tantalum, are being evaluated in clinical and experimental studies. The Medtronic Wiktor stent (Medtronic Inc., Minneapolis, MN, USA) is made of tantalum and has a flexible, open-weave configuration. It is $20 \mathrm{~mm}$ long and has a wire thickness of $0.125 \mathrm{~mm}$ (Figure 3). The Cordis Coronary Stent and Delivery System (Cordis Corporation, Miami, FL, USA), like the Medtronic Wiktor stent, is a coiled, tantalum device 16-22 $\mathrm{mm}$ long, with a wire thickness of $0.125 \mathrm{~mm}$. The Boneau $I I$ is a stainless-steel stent under early experimental evaluation ( $\Lambda$ nwar et al. 1990), and the Strecker stent (Medi-Tech, Watertown, MA, USA) is a tantalum, interwoven wire-mesh stent that has been used in Furopean clinical trials for the treatment of peripheral vascular stenoses (Becker 1991).

\section{Self-Expanding Stents}

The Wallstent (Medinvent SA, Lausanne, Switzerland) is stainless steel and varies in length from 15 to $30 \mathrm{~mm}$. The woven mesh device is delivered on a catheter, on which it is compressed by a doubledover retaining membrane (Figure 4). Gradual withdrawal of the membrane allows the stent to expand to a predetermined size and to the shape of the

Figure 3. The Medtronic Wiktor coronary stent.

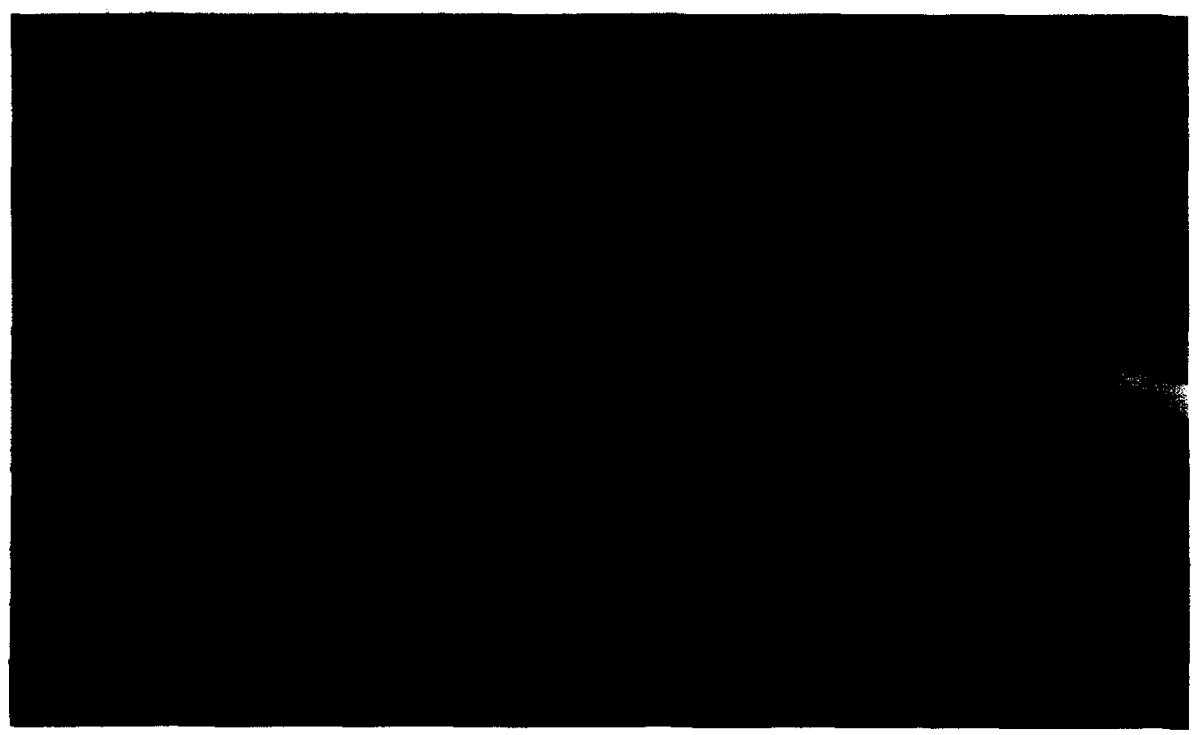

stented vessel. Polymer-coated versions of the stent have recently been implanted in experimental animal models.

\section{Thermal Memory Stents}

Some metal alloys, such as nickeltitanium (nitinol), undergo a striking conformational change when exposed to changes in temperature. These metals can be annealed to a desired configuration, diameter, and length at high temperatures. At room temperature, the device can be shaped to a second, lowprofile, flexible configuration that allows it to be readily delivered to the site of the coronary stenosis. Subsequent rewarming by heated normal saline causes the metal to resume its original crystalline structure and configuration. The feasibility of deploying such devices has been demonstrated in experimental studies (Sutton et al. 1990), but clinical studies have not yet been performed.

\section{- Indications for Metallic Stent Implantation}

The development of intravascular stenting as an alternative to coronary balloon angioplasty was based on three potential clinical indications for this approach: (a) to optimize the initial angiographic results of the intervention, (b) to prevent restenosis, and (c) to manage severe medial dissection and abrupt arterial closure following coronary balloon angioplasty.
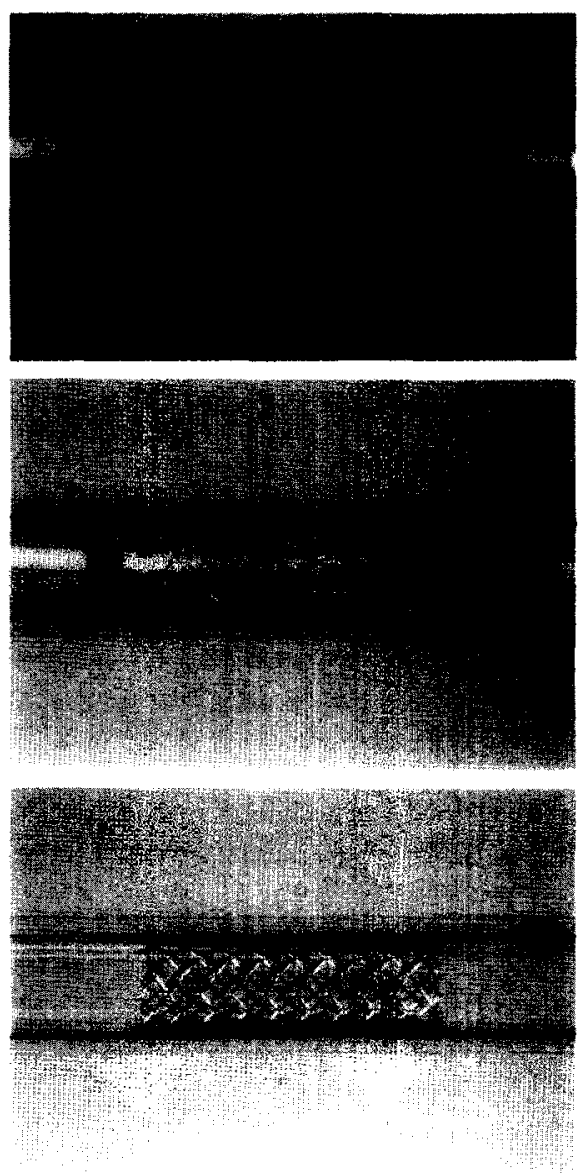

Figure 4. The self-expanding Wallstent before, during, and after removal of the retaining membrane. From Muller and Ellis (1990b).

\section{Initial Angiographic Results}

With careful patient selection, acute success rates for metallic stent implantation have been high (90\%-95\%) and, in most series, immediate angiography has shown excellent results with a mean residual stenosis severity of $<20 \%$ by quantitative coronary angiography (Schatz et al. 1991; Levine et al. 1990). Although randomized comparisons between coronary stenting and balloon angioplasty have not yet been performed, one case control study suggested that the residual luminal diameter may be greater following stent implantation than following balloon angioplasty (Muller et al. 1990a).

\section{Prevention of Restenosis}

Early, nonrandomized data from several centers suggest that, in selected patient populations, the incidence of restenosis may be lower following intravascular stenting than following balloon angioplasty. In one series of 83 paticnts 


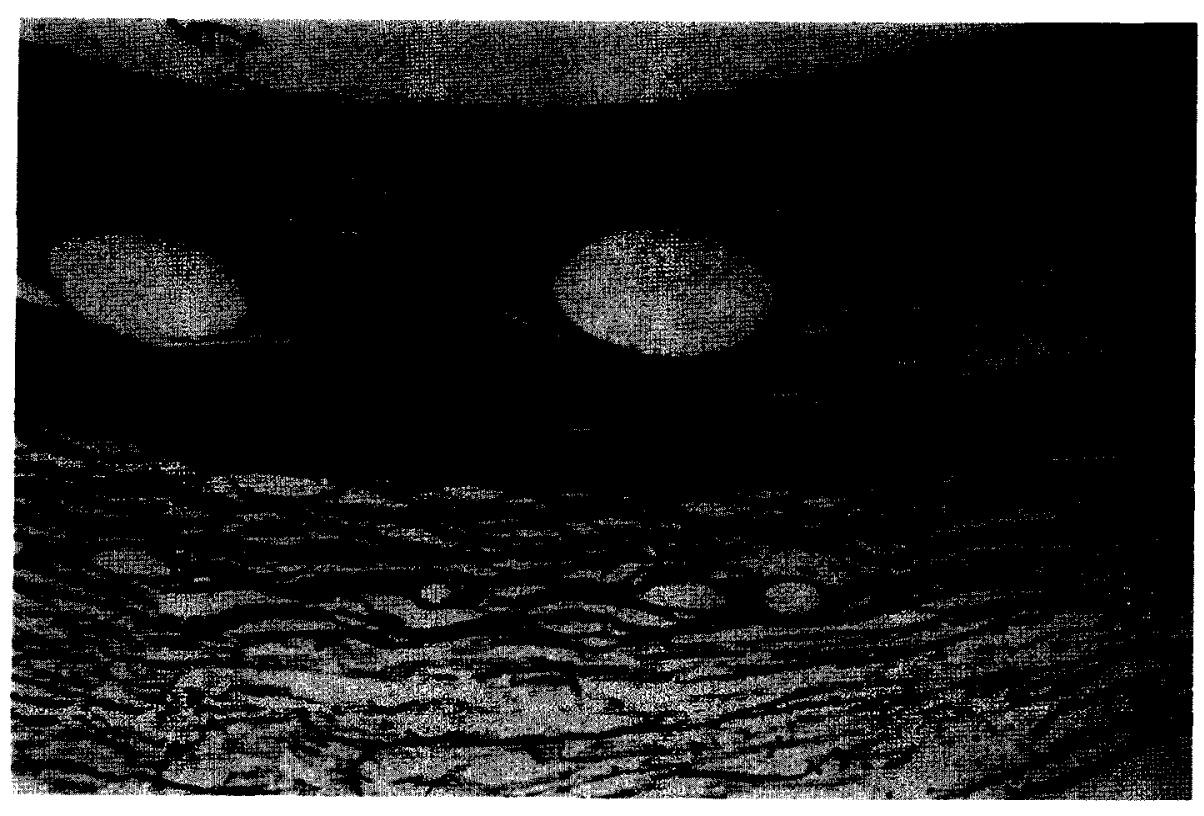

Figure 5. Histologic section 3 months following implantation of a coronary Wallstent showing intimal proliferation overlying and between the struts of the stent. Courtesy of the Schneider US Stent Division (Plymouth, MN, USA). From Muller and Ellis (1990b).

(Fajadet et al. 1990), the incidence of angiographic restenosis (defined as a stenosis $\geq 50 \%$ luminal diameter) 6 months after coronary stenting (PalmazSchatz device) was $16.9 \%$. A $17 \%$ incidence of restenosis was also noted in a series of 18 patients with single right coronary artery stents (Levine et al. 1990). However, the incidence of restenosis appears to be highly dependent on the size of the stented vessel and on the length of the lesion. In particular, the use of multiple, overlapping stents (Ellis et al. 1990b; Levine et al. 1990) or stent implantation in arteries of $<3.2 \mathrm{~mm}$ in diameter (Ellis et al. 1990b) have been associated with restenosis rates of $>50 \%$.

The apparent reduction in the incidence of restenosis in large arteries with discrete stenoses has been attributed to a greater initial increase in coronary luminal diameter, rather than to a reduction in the severity of the intimal proliferative response (Ellis ct al. 1990a). Some degree of neointimal thickening appears to be invariable. Experimental studies have shown that, following stent implantation, the metallic struts of the device rapidly become covered with a fine layer of confluent endothelial cells (Schatz et al. 1987). Thereafter, the intimal thickness overlying and between the stent struts increases progressively, to peak $\sim 2-3$ months after stent implantation (Figure
5). At 6 months, the intimal thickness overlying the stent typically ranges from 100 to $450 \mu \mathrm{m}$ (Roubin et al. 1987; Sigwart et al. 1987). Thus, the implantation of metallic stents does not prevent the reparative response of the vessel wall to injury, but instead may reduce its physiologic significance by maximizing the initial coronary luminal diameter.

Figure 6. Successful management of abrupt right coronary closure by insertion of three

Gianturco-Roubin stents. From Muller and Ellis (1990b).
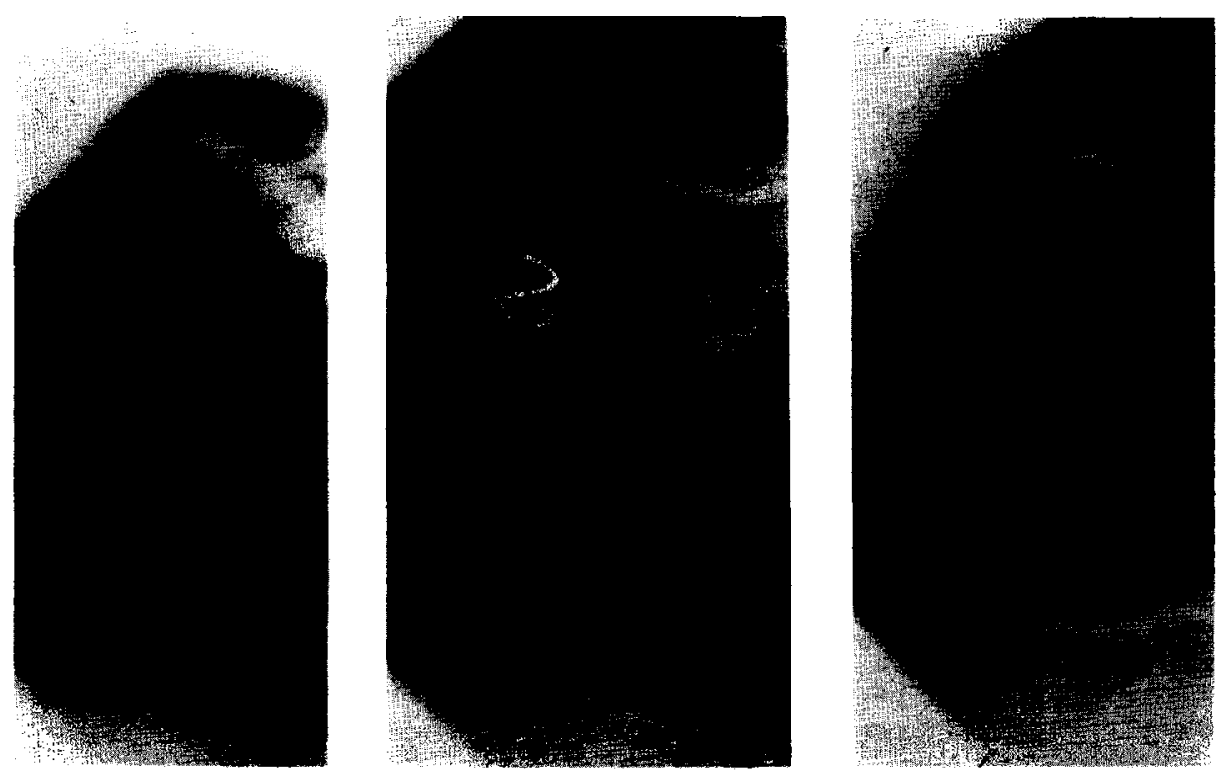
with a satisfactory long-term outcome remains to be determined. In one series of 32 patients with long-term angiographic follow-up, for example, the incidence of restenosis within 6 months of stent implantation for actual or threatened abrupt closure was $44 \%$ (Roubin et al. 1990b). These findings require confirmation in larger studies and may actually

Although relatively uncommon, abrupt closure following balloon angioplasty is associated with a high morbidity and a relatively high mortality (Detre et al. 1989). The availability of endovascular stents to seal arterial dissections and to restore rapidly coronary flow greatly increases the overall safety of percutaneous coronary interventions and the confidence with which high-risk interventions can be undertaken. Each of the clinically available metallic stents has been used successfully for the management of abrupt closure or of threatened closure associated with a suboptimal postangioplasty angiographic appearance (Sigwart et al. 1987; Roubin et al. 1990a; Schatz et al. 1990). Intravascular stents were initially used in this setting as a bridge to emergency coronary artery bypass graft surgery, but more recently coronary stenting has been used to obviate the need for urgent surgery (Figure 6). Whether this approach is associated 
be no worse than following successful balloon angioplasty associated with transient abrupt vessel closure (Ba'albaki et al. 1990). An alternative to permanent intravascular stenting for abrupt closure may be the use of temporary, retrievable devices. Experience with one such device (Didier et al. 1991) suggests that temporary, prolonged compression may be adequate to seal a dissection flap successfully and to avoid the morbidity associated with permanent stenting or urgent coronary artery bypass graft surgery.

\section{- Major Limitations of Metallic Stents}

In their current designs, metallic stents are limited principally by their inflexibility and by the need for several months of intensive anticoagulation therapy to prevent early thrombotic closure. The low flexibility of the devices precludes their use in tortuous, heavily calcified vessels and demands the use of large-caliber guiding catheters to provide adequate support during deployment. This not only increases the potential for guidecatheter-induced ostial dissections, but also increases the likelihood of femoral access site hemorrhagic complications. Subacute stent thrombosis remains a significant hazard. In the absence of an intensive anticoagulation regimen, thrombotic closure of the stented vessel occurs frequently during the first 2-3 weeks. In a series of 213 patients in whom PalmazSchatz stents were implanted electively, the incidence of subacute closure was $18 \%$ in 39 patients who received periprocedural heparin, aspirin, dextran, and dipyridamole compared with $0.6 \%$ in the remaining patients, all of whom were fully anticoagulated for 3 months (Schatz et al. 1991). A similarly high early thrombosis rate ( $25 \%$ in patients inadequately anticoagulated) has been reported for the Medtronic Wiktor stent (Bertrand et al. 1990) and for the Wallstent (Serruys et al. 1991). The incidence is likely to be particularly high in patients with unstable angina and intracoronary thrombus (Bertrand et al. 1990; Serruys et al. 1991). It is imperative, therefore, that patients in whom stents have been implanted be fully anticoagulated for at least 4-6 weeks, a period that corresponds to the time required for complete endothelialization of the metal struts. Unfortunately, the need for such an intensive anticoagulation regimen in- creases the potential for bleeding complications, and periaccess site, retroperitoneal, and gastrointestinal bleeding has occurred relatively commonly in most centers during early experience with stent implantation. Furthermore, the need for a prolonged hospital stay and careful monitoring of the patients' anticoagulant therapy may also increase the cost of the procedure (Dick et al. 1990). Whether this apparently greater cost is justifiable on the basis of improved long-term results remains to be evaluated.

\section{- Polymer Stents}

The limitations of metallic intravascular stents described above and concerns about the unknown long-term effects of permanent intravascular devices have led to the search for biodegradable materials with the structural characteristics of metallic stents, but without the potential for adverse long-term sequelae. A variety of synthetic polymers and delivery systems have been evaluated. One system uses a temperature-sensitive, fenestrated, biodegradable polymer that is deployed on a balloon catheter (Slepian 1990). The polymer is initially heated to $60^{\circ} \mathrm{C}$ with normal saline, which allows it to be molded to the desired size and shape by balloon inflation within the treated vessel. Subsequent cooling causes the polymer to assume its original solid phase, which has sufficient strength to oppose the recoil of the dilated vessel. The composition of the polymer can be altered to vary the rate of its degradation from several weeks to many months. In addition to avoiding the possible complications of permanent metallic devices, this approach has the potential advantages of minimizing blood flow turbulence and of providing a barrier to circulating mitogenic and thrombogenic factors. Whether it will in fact reduce the incidence of restenosis, however, remains to be determined. Few data have yet been reported for other polymeric stent designs. Two selfexpanding devices have been evaluated experimentally and reported in small series. The implantation of a biodegradable L-polylactide stent in canine femoral arteries was associated with satisfactory early patency in one study (Chapman et al. 1990). A second polymeric stent, made from polyethylene tetraphthalate, was initially reported to be easily implanted and biocompatible (Murphy et al. 1990), but, in longer-term follow-up studies, the stent was shown to induce a severe local inflammatory reaction, extensive neointimal proliferation, and coronary occlusion (J.G. Murphy, personal communication, 1991).

In addition to the potential for polymers to intensify the proliferative response, several other factors limit the development of polymeric stents. These include the need for a reliable delivery system, the need for adequate radial strength to withstand elastic recoil and vasoconstriction without increasing the bulk of the stent, and the decay characteristics (that is, surface versus bulk erosion) of biodegradable polymers. The only degradable polymers in common use display bulk erosion that results in degradation of the matrix interior and the potential for microembolism and, if drug impregnated, for dose dumping. In contrast, surface-eroding systems degrade in a more predictable and more readily controlled manner (Langer 1990).

\section{- Prospects for Endovascular Pharmacologic Therapy}

Ideally, the advantages of mechanical scaffolding of coronary arteries by metallic or polymeric stents should be combined with local pharmacologic therapy to avoid the need for systemic anticoagulation and to inhibit the intimal proliferative response. Although still in their infancy, several such approaches have been evaluated, including the bonding of antithrombotic or fibrinolytic agents to metallic stents or synthetic grafts, the local delivery of drugcontaining microspheres, the coating of stents with genetically modified endothelial cells, and the use of drug-eluting polymeric matrices.

\section{Heparin Bonding}

Heparin bonding has been used to reduce the thrombogenicity of several indwelling intravascular devices including pulmonary artery catheters (Hoar et al. 1981; Mangano 1982) and the extracorporeal circuits used for cardiopulmonary bypass (Lindsay et al. 1976). Preliminary experience with heparin-bonded tantalum stents implanted in porcine carotid arteries has been reported (Cavender et al. 1990). These investigators noted no difference in the incidence of 
thrombosis and intimal proliferation between heparin-bonded and nonheparinized stents, but very little thrombotic or proliferative response was apparent in either group. Attempts to bond other, more potent, antithrombin agents such as hirudin or its synthetic derivative, hirulog, that are currently under way may reduce the thrombogenicity of metallic stents and, perhaps, reduce the incidence of restenosis following stent implantation. Tissue plasminogen activator (tPA) has also been noncovalently bound to synthetic vascular grafts and shown to retain fibrinolytic activity (Harvey et al. 1989). In the presence of plasma, however, the fibrinolytic activity of the bound IPA was decreased, presumably due to the action of circulating plasminogen-activator inhibitors.

\section{Local Drug-Containing Microspheres}

A second means of delivering local antithrombotic or antiproliferative agents to the site of arterial injury is by thermal energy-mediated adherence of albumin microspheres to the vascular wall. McMath et al. (1990) used laser thermal energy to apply heparin-entrapped fluorescent albumin microspheres to the endothelium after balloon angioplasty. Adherence of the fluorescent microspheres was apparent for up to $24 \mathrm{~h}$ after the procedure. A potential limitation of this approach is the effect of the laser energy itself on smooth muscle cell proliferation. Preliminary follow-up data from the use of laser balloon angioplasty for abrupt coronary closure suggest that the restenosis rate may, in fact, be considerably higher than in patients treated by conventional balloon angioplasty (Mast et al. 1990).

\section{Endothelialized Stents}

A more physiologic approach to the inhibition of thrombosis and neointimal thickening may be to promote early endothelialization of the metallic stent struts. Under normal circumstances, the vascular endothelium plays a critical role in the maintenance of vessel patency by influencing vascular tone, inhibiting or promoting platelet adhesion and thrombosis; it may also inhibit proliferation of medial smooth muscle cells through the release of heparinlike glycosaminoglycans (Castellot et al. 1987). The feasibility of in vitro endothelialization of metallic stents has been reported (Van der
Giessen et al. 1988; Dichek et al. 1989). In the study by Dichek et al., subsequent balloon dilatation was associated with loss of endothelial cells on the luminal surface of the stent, but satisfactory preservation of cells on the exterior and lateral surfaces. The effects of this process on in situ thrombus formation have not yet been examined. Endothelial seeding of other vascular prostheses has had variable effects on the incidence of subsequent thrombus formation in man (Fasol et al. 1989; Ortenwall et al. 1990). Whether this approach will also reduce the severity of neointimal hyperplasia, as suggested by one study in which endarterectomized canine carotid arteries were seeded with endothelial cells (Bush et al. 1987), also remains to be determined.

In addition to simply covering the metal surface, endothelial seeding may provide other means of reducing the thrombogenicity of stents and the intimal thickening that follows their implantation. Several authors have described the modification of endothelial cell function by gene transfer. In the study by Dichek et al. (1989), genes encoding the synthesis of tPA and $\beta$ galactosidase were inserted into endothelial cells by retrovirus-mediated transfer prior to seeding onto the metallic stent surface. Secretion of tPA and synthesis of $\beta$-galactosidase by the transduced and seeded endothelial cells was subsequently confirmed. Direct in vivo transfection of endothelial cells has also been reported (Nabel et al. 1990) and genetically modified endothelial cells have been used to cover prosthetic vascular grafts (Wilson et al. 1989). This approach may allow the delivery at the site of stent implantation of the genetic material coding not only for the expression of plasminogen activators, but also for endothelial cell growth factors, angiogenic factors, or inhibitors of smooth muscle cell proliferation. Several factors may, however, limit the application of this exciting technology to the management of patients in the cardiac catheterization laboratory. Issues that must be addressed include the need for harvesting autologous endothelial cells well in advance of planned interventional procedures, the safety of using even replicationdefective retroviruses for gene transfer, the relative merits of ex vivo seeding of metallic stents compared with in vivo direct gene transfer to adjacent endothe- lial cells, means by which direct gene transfer can be accomplished without prolonged coronary occlusion and myocardial ischemia, and the duration of expression of recombinant genes in vivo.

\section{Drug-Eluting Polymers}

The approach with perhaps the greatest potential (in the near future) for prolonged local pharmacologic therapy is the use of controlled-release polymeric matrices. These may be used to coat metallic stents or, ideally, as endovascular stents themselves. Both degradable (for example, polyurethane, silicone rubber, and ethylene vinyl acetate) and nondegradable polymers (for instance, polyanhydrides and polyglycolic-polylactic acid) have been used experimentally to administer local antiinflammatory, antiarrhythmic, and antibiotic agents for a variety of cardiovascular indications, including the inhibition of bioprosthetic cardiac valve calcification, inhibition of ventricular arrhythmias, and the prevention of heart-transplant rejection (Levy et al. 1990). Heparineluting ethylene vinyl acetate copolymers, placed around the adventitial surface of balloon-injured rat carotid arteries, were also shown in one study to inhibit smooth muscle cell proliferation and neointimal thickening (Edelman et al. 1990). The development of endovascular, drug-eluting polymers has, however, been limited by several technical considerations. In addition to the limitations outlined above for polymer stents, incorporation of drugs into sustained-release polymer coatings for metallic stents requires attention to the effects of preparation of the polymer on the activity of the incorporated agent, the adequacy of drug concentrations at the vessel surface between the metal struts, the duration of drug delivery from the small-volume polymer coating, and the elastic characteristics of the polymer during balloon dilatation.

\section{- Conclusions}

The use of intravascular, metallic stents appears to improve initial angiographic appearances and dimensions following coronary artery dilatation and provides a reliable treatment for the acute management of medial dissection and abrupt closure. Preliminary data suggest that, in certain subgroups, stenting may also 
reduce the incidence of recurrent stenosis. The widespread application of endovascular stenting in these patients has been limited, however, by the need for intensive anticoagulation. Stenting may become a first-line treatment for obstructive coronary arterial disease in selected patients if the thrombogenic potential of the devices can be substantially reduced by local antithrombutic or fibrinolytic therapy. In other patients, the usc of local pharmacologic or genetransfer therapies, alone or in combination with implantable endovascular devices, may eventually be a valuable means of inhibiting the fibroproliferative response that appears to follow all forms of arterial injury.

\section{References}

Anwar A, Stertzer SH, Webb J, et al.: 1990. Animal experience with Boneau II: a new intracoronary stent device [abst]. Circulation 82(Suppl 3):III-658.

Austin GE, Ratliff NR, Hollman J, Tabei S, Phillips DF: 1985. Intimal proliferation of smooth muscle cells as an explanation for recurrent coronary artery stenosis after percutaneous transluminal coronary angioplasty. J Am Coll Cardiol 6:369-375.

Ba'albaki HA, Weintraub WS, Tao X, et al.: 1990. Restenosis after acute closure and successful reopening: implications for new devices [abst]. Circulation 82(Suppl 3):III314.

Becker GJ: 1991. Intravascular stents: general principles and status of lower-extremity arterial applications. Circulation 83(Suppl 1):I-122-I-136.

Bertrand M, Kober G, Scheerder Y, Uebis R, Wiegand V: 1990. Initial multi-center human clinical experience with the Medtronic (8) Wiktor coronary stent [abst]. Circulation 82:III-541.

Bush HL, Jakubowski JA, Sentissi JM, Curl GR, Hayes JA, Deykin D: 1987. Neointimal hyperplasia occurring after carotid endarterectomy in a canine model: effect of endothelial cell seeding vs perioperative aspirin. J Vasc Surg 5:18-25.

Califf RM, Ohman EM, Frid DJ, et al.: 1990. Restenosis: the clinical issues. In Topol EJ, ed. Textbook of Interventional Cardiology. Philadelphia, WB Saunders, pp 363-394.

Castellot JJ, Wright TC, Karnovsky MJ: 1987. Regulation of vascular smooth muscle cell growth by heparin and heparan sulphates. Sem Thromb Hemost 13:489-503.

Cavender JB, Anderson P, Roubin GS: 1990. The effects of heparin bonded tantalum stents on thrombosis and neointimal proliferation [abst]. Circulation 82(Suppl 3):III541.

Chapman GD, Gammon RS, Bauman RP, et al.: 1990. A bioabsorbable stent: initial experimental results [abst]. Circulation 82(Suppl 3):III-72.

Detre K, Holubkov R, Kelsy S, ct al.: 1989. One year follow-up results of the 1985-1986 Second National Heart, Lung and Blood Institute percutaneous transluminal coronary angioplasty registry. Circulation 80:421428.

Dichek DA, Neville RF, Zwiebel JA, Freeman SM, Leon MB, Anderson WF: 1989. Seeding of intravascular stents with genetically engineered endothelial cells. Circulation 80:1347-1353.

Dick RJ, Popma JJ, Muller DW, Burek KA, Topol EJ: 1991. In-hospital costs associated with new percutaneous coronary devices. Am J Cardiol 68 (in press).

Dotter CT: 1969. Transluminally-placed coilspring endarterial tube grafts: long-term patency in canine popliteal artery. Invest Radiol 4:329-332.

Edelman ER, Adams DH, Karnovsky MJ: 1990. Effect of controlled adventitial heparin delivery on smooth muscle cell proliferation following endothelial injury. Proc Natl Acad Sci USA 87:3773-3777.

Ellis SG, Fischman DL, Hirshfeld JW, et al:: 1990a. Mechanism of stent benefit to limit restenosis following coronary angioplasty: regrowth vs larger initial lumen [abst]. Circulation 82(Suppl 3):III-540.

Ellis SG, Savage M, Baim D, et al.: 1990b. Intracoronary stenting to prevent restenosis: preliminary results of a multicenter study using the Palmaz-Schatz stent suggest benefit in selected high risk patients [abst]. J Am Coll Cardiol 15(Suppl A):118A.

Essed $\mathrm{CE}$, Van den Brand $\mathrm{M}$, Becker $\mathrm{AE}$ : 1983. Transluminal coronary angioplasty and early restenosis: fibrocellular occlusion after wall laceration. Br Heart J 49:393396.

Fajadet JC, Marco J, Cassagneau BG, Bobert GP, Jordan CG, Laurent JP: 1990. Restenosis following successful single Palmaz-Schatz stent implantation [abst]. Circulation 82(Suppl 3):III-314.

Fasol R, Zilla P, Deutsch M, Grimm M, Fischlein T, Laufer G: 1989. Human endothelial seeding: evaluation of its effectiveness by platelet parameters after one year. $J$ Vasc Surg 9:432-436.

Fischell TA, Derby G, Tse TM, Stadius ML: 1988. Coronary artery vasoconstriction routinely occurs after percutaneous transluminal coronary angioplasty: a quantitative arteriographic analysis. Circulation 78:13231334.
Gaspard Ph, Didier B, Lienhart T, Frieh JPh: 1991. Temporary stenting for abrupt closure during coronary angioplasty [Letter]. Lancet 337:1226.

Harvey RA, Kim HC, Pincus J, Trooskin SZ, Wilcox JN, Greco RS: 1989. Binding of tissue plasminogen activator to vascular grafts. Thromb Haemost 61:131-136.

Hoar PF, Wilson RM, Mangano DT, Avery GJ, Szarnicki RJ, Hill JD: 1981. Heparin bonding reduces the thrombogenicity of pulmonary-artery catheters. N Engl J Med 305:993995.

Karsch KR, Haase KK, Voelker W, Baumbach A, Mauser M, Seipel L: 1990. Perculaneuus coronary excimer laser angioplasty in patients with stable and unstable angina pectoris: acute results and incidence of restenosis during 6-month follow-up. Circulation 81:1849-1859.

Langer R: 1990 . New methods of drug delivery. Science 249:1527-1533.

Levine MJ, Leonard BM, Burke JA, et al.: 1990. Clinical and angiographic results of balloon-expandable intracoronary stents in right coronary artery stenoses. J Am Coll Cardiol 16:332-339.

Levy RJ, Johnston TP, Sintov A, Golomb G: 1990. Controlled release implants for cardiovascular disease. J Control Release 11:245254.

Lindsay RM, Rourke J, Reid B, et al.: 1976. Platelets, foreign surfaces, and heparin. Trans Am Soc Artif Intern Organs 22:292295.

Liu MW, Roubin GS, King SB: 1989. Restenosis after coronary angioplasty: potential biologic determinants and role of intimal hyperplasia. Circulation 79:1374-1387.

Mangano DT: 1982. Heparin bonding and long-term protection against thrombogenesis [Letter]. N Engl J Med 307:894.

Mast G, Plokker T, Bal E, Ernst S, Gin MTJ, Ascoop C: 1990. Laser balloon angioplasty does not reduce restenosis rate in type $A$ and $\mathrm{B}$ coronary lesions [abst]. Circulation 82(Suppl 3):III-313.

McMath LP, Kundu SK, Spears JR: 1990. Experimental application of bioprotective materials to injured arterial surfaces with laser balloon angioplasty [abst]. Circulation 82(Suppl 3):III-72.

Muller DWM, Ellis SG, Debowey DL, Topol EJ: 1990a. Quantitative angiographic comparison of the immediate success of coronary angioplasty, coronary atherectomy and endoluminal. Am J Cardiol 66:938-942.

Muller DWM, Ellis SG: 1990b. Advances in coronary angioplasty: endovascular stents. Coronary Artery Dis 1:438-448.

Murphy JG, Schwartz RS, Kennedy K, et al.: 1990. A new, biocompatible polymeric coronary stent: design and early results in a pig 
model [abst]. J Am Coll Cardiol 15(Suppl A):105A.

Nabel EG, Plautz G, Nabel GJ: 1990. Sitespecific gene expression in vivo by direct gene transfer into the arterial wall. Science 249:1285-1288.

Ortenwall P, Wadenvik H, Kutti J, Risberg B: 1990. Endothelial cell seeding reduces thrombogenicity of Dacron grafts in humans. J Vasc Surg 11:403-410.

Roubin GS, Robinson KA, King SB, et al.: 1987. Early and late results of intracoronary arterial stenting after coronary angioplasty in dogs. Circulation 76:891-897.

Roubin GS, King SB, Douglas JS, Lembo NJ, Robinson KA: 1990a. Intracoronary stenting during percutaneous transluminal coronary angioplasty. Circulation 81 (Suppl 4):IV92-IV-100.

Roubin GS, Hearn JA, Carlin SF, Lembo NJ, Douglas JS, King SB: 1990b. Angiographic and clinical follow-up in patients receiving a balloon expandable, stainless steel stent (Cook, Inc.) for prevention or treatment of acute closure after PTCA [abst]. Circulation 82(Suppl 2):II-756.

Safian RD, Gelbfish JS, Erny RE, Schnitt SJ, Schmidt DA, Baim DS: 1990. Coronary atherectomy: clinical, angiographic, and histological findings and observations regarding potential mechanisms. Circulation 82:69-79.

Schatz RA, Palmaz C, Tio FO, Garcia F, Garcia O, Reuter SR: 1987. Balloon expandable intracoronary stents in the adult dog. Circulation 76:450-457.

Schatz RA, Goldberg S, Leon MB, Fish D, Hirshfeld JW, Walker CM: 1990. Coronary stenting following "suboptimal" coronary angioplasty results [abst]. Circulation 82(Suppl 3):III-540.

Schatz RA, Baim D, Leon M, et al.: 1991. Clinical experience with the Palmaz-Schatz coronary stent: initial results of a multicenter study. Circulation 83:148-161.

Serruys PW, Strauss BH, Beatt KJ, et al.: 1991. Angiographic follow-up after placement of a self-expanding coronary artery stent. N Engl J Med 324:13-17.

Sigwart U, Puel J, Mirkowittch V, Joffre F, Kappenberger L: 1987. Intravascular stents to prevent occlusion and restenosis after transluminal angioplasty. $\mathrm{N}$ Engl J Med 316:701-706.

Slepian MJ: 1990. Polymeric endoluminal paving and sealing: therapeutics at the crossroads of biomechanics and pharmacology. In Topol EJ, ed. Textbook of Interventional Cardiology. Philadelphia, WB Saunders, pp 647-672.

Sutton CS, Tominaga $\mathrm{R}$, Harasaki $\mathrm{H}$, et al.: 1990. Vascular stenting in normal and atherosclerotic rabbits: studies of the intravascular endoprosthesis of titanium-nickel alloy. Circulation 81:667-683.

Van der Giessen WJ, Serruys PW, Visser WJ, Verdouw PD, Van Schajkwijk, Jongkind JF: 1988. Endothelialization of intravascular stents. J Interven Cardiol 1:97-108.

Waller BF: 1985 . Coronary luminal shape and the arc of disease-free wall: morphologic observations and clinical relevance. $\mathbf{J}$ Am Coll Cardiol 6:1100-1101.

Waller BF, Pinkerton CA, Rothbaum DA, et al.: 1990. Restenosis tissue following hot tip laser, excimer laser, primary atherectomy and balloon angioplasty procedures: histologically similar intimal proliferation in 33 atherectomy patients [abst]. Circulation 82(Suppl 3):III-312.

Wilson JM, Birinyi LK, Salomon RN, Libby P, Callow AD, Mulligan RC: 1989 . Implantation of vascular grafts lined with genetically modified endothelial cells. Science 244:1344-1346.

TCM

\section{Announcing the most up to date reference available today}

\section{ACUTE MYOCARDIAL INFARCTION}

\section{Current Topics in Cardiology Series}

Edited by Bernard J. Gersh, MB, ChB, DPhil, Consultant in Cardiovascular Diseases and Internal Medicine and Professor of Medicine, Mayo Clinic and Mayo Medical School, Rochester, Minnesota; and Shahbudin H.

Rahimtoola, MB, FRCP, George C. Griffith Professor of Cardiology, Professor of Medicine, and Chief, Division of Cardiology, University of Southern California, Los Angeles, California

Earlier diagnosis and more effective treatment have radically altered the management of patients with acute myocardial infarction.

Additionally, there has been an explosion of data about pathophysiology, characterization of clinical subgroups, and cardiac rehabilitation. Synthesizing these recent developments, Acute Myocardial Infarction provides an invaluable tool for ensuring optimal patient care.

This state-of-the-art work on the diagnosis and management of acute myocardial infarction provides complete coverage and is referenced through early 1990 . Over 30 chapters offer in-depth discussions- of such topics as:

- acute ischemic syndromes

- radionuclide imaging techniques

- pharmacologic management

- mechanical complications
- thrombolytic therapy

- PTCA and bypass surgery

Order today. A significant, timely and substantial resource, Acute Myocardial Infarction belongs in your library!

0-444-01545-0 November 1990524 pages, 170 line drawings and 135 photographs, including 8 color plates cloth $\$ 89.00$

(Dfl. 195.00 outside North America)

Send orders to:

in North America

Elsevier Science Publishing Co., Inc.

P.O. Box 882, Madison Square Station

New York, NY 10159

outside North America

Elsevier Science Publishers

Box 211, 1000 AE Amsterdam

The Netherlands

For faster service, call or fax today to place your order:

Tel. No.: (212) 633-3650

Fax No.: (212) 633-3990 